\title{
0 Exemplo de Uma Dramaturgia Prospectiva e Documentária Para Ça ira (1) Fin de Louis, de Joël Pommerat
}

\author{
Marion Boudier \\ Université de Picardie Jules Verne, Amiens, França \\ E-mail: marion.boudier@u-picardie.fr \\ Tradução: Clóvis D. Massa \\ Universidade Federal do Rio Grande do Sul \\ E-mail: clovisdmassa@gmail.com
}

\section{Resumo}

Este artigo propõe uma descrição e uma teorização do trabalho dramatúrgico realizado por Marion Boudier ao lado do autor-encenador Joël Pommerat para a criação de Ça ira (1) Fin de Louis (criado em 2015 e apresentado na Mostra Internacional de Teatro de São Paulo em 2016). Como trabaIhar a partir dos arquivos da Revolução francesa para acompanhar um autor-encenador que escreve seus textos com a cena durante os ensaios? Marion Boudier apresenta o que ela denomina de «dramaturgia prospectiva e documentária». Este acompanhamento da escritura se distingue das práticas clássicas da dramaturgia. Com efeito, para entrar na escritura, Joël Pommerat dirigiu seus atores em improvisações longamente preparadas e nutridas pour uma importante documentação histórica: em vez de esclarecer um texto prévio com a finalidade de transpô-lo para a cena, o trabalho dramatúrgico consiste então, nesse caso, em propor uma matéria documental pertinente para o tema escolhido e potencialmente rica para o teatro, então reagir a suas evoluções cênicas. Desse modo, a dramaturgia é uma espécie de investigação, levada a serviço do autor-encenador e de seus atores ao longo do processo de criação.
This article proposes a description and theorization of the dramaturgical work done by Marion Boudier alongside author-director Joël Pommerat for the creation of Ça ira (1) Fin de Louis (created in 2015 and represented at São Paulo International Theater Exhibition in 2016). How to work from the archives of the French Revolution to accompany an author-director who writes his texts with the scene during rehearsals? Marion Boudier presents what she calls "prospective and documentary dramaturgy". This accompaniment of scripture is distinguished from classical dramaturgy practices. In order to enter scripture, Joël Pommerat directed his actors in long-prepared and nourished improvisations for an important historical documentation. Rather than clarifying a previous text with the purpose of transposing it into the scene, the dramaturgical work then consists in proposing a documentary material relevant to the chosen theme and potentially resourceful for the theater, then reacting to its scenic evolutions. This way, the dramaturgy is a kind of investigation, carried out at the service of the author-director and his actors throughout the process of creation.
Dramaturgia. Prospecção. Documentação (arquivo). Escritura de palco. Revolução Francesa.
Keywords

Dramaturgy. Prospection. Documentation (archive). Stage writing. French Revolution.

\section{Palavras-Chave}


Acompanho Joël Pommerat desde 2013 como colaboradora na dramaturgia de projetos de teatro e ópera. Este artigo propõe uma descrição e uma teorização do trabalho do dramaturgo por meio do exemplo de Ça ira (1) Fin de Louis, criado em Mons - Capital da Cultura em 2015. Essa contribuição é inspirada em uma palestra proferida durante a Bienal das Escrituras do Real em Marselha, em abril de 2018. Ela sintetiza algumas análises desenvolvidas mais amplamente no livro Avec Joël Pommerat, volume 2, publicado pelas edições Actes Sud e laureado com o Prêmio do Sindicato da Crítica - Melhor Livro Sobre Teatro - em 2019.

Ça ira (1) Fin de Louis, de Joël Pommerat, é uma ficção política contemporânea que remonta aos primórdios da Revolução Francesa, desde a crise econômica e a tentativa de reforma tributária em 1786-1787 até o surgimento da contra-revolução nos anos 1790-91. Essa arqueologia do regime democrático é realizada por catorze atores que, durante as $4 \mathrm{~h} 30$ do espetáculo, incorporam mais de sessenta personagens, principalmente oradores políticos, membros da comitiva real, deputados nos Estados Gerais e depois na Assembleia Nacional, parisienses reunidos em assembleias de bairro. Ao imergir o público nesses debates por meio de uma cenografia abrangente (a sala se torna a Assembleia), Ça ira (1) Fin de Louis oferece uma história viva, reveladora de várias filiações entre ontem e hoje e apresenta questões universais como a liberdade, a relação com a violência, a representação política... Os espectadores brasileiros que assistiram ao espetáculo em São Paulo no momento da destituição da presidenta Dilma Roussef provavelmente conseguiram encontrar nele proposições ou situações políticas e humanas que eram próximas deles. Em cada cidade e país onde Ça ira (1) Fin de Louis foi apresentado, ocorreram ecos entre os eventos revolucionários e a realidade ou o contexto. No entanto, é de 1789 que se trata: como Joël Pommerat reativa esse mito? Que abordagem de escrita inventar para colocar os espectadores "no presente do passado"? Não sou historiadora, mas dramaturgista. Em que consistiu meu trabalho no seio dessa criação?

Dramaturgia é um termo polissêmico usado para descrever duas práticas distintas: a composição das peças (o trabalho do autor) e o pensamento de sua passagem para a cena (trabalho do Dramaturg em alemão ou do dramaturgista em espanhol - o francês tem apenas um termo, fonte de confusão). Joël Pommerat tem a particularidade de escrever seus espetáculos em estreita conexão com a cena, ao mesmo tempo em que os ensaia e os encena com seus atores. Nesta maneira de criar, a escrita e a encenação são inventadas ao mesmo tempo durante os ensaios. Não indo mais o texto em direção à cena, mas a cena em direção ao texto, é a abordagem criadora que faz o trabalho. (BOUDIER, 2015) Esse processo de escrita com a cena desloca o papel do dramaturgista. Com um "escritor de palco" (TACKELS, 2016) como Joël Pommerat, a atividade teatral deixa de ser uma arte de "dois tempos" (GOUHIER, 1989), a escrita de um texto e depois a encenação desse texto), dois tempos que permitem, na maioria dos casos, distinguir dramaturgo-autor (Dramatiker) e dramaturgo-maiêutico (Dramaturg). Como o texto é escrito ao mesmo tempo em que sua encenação é elaborada, a "composição" e o "pensamento da transição para a cena" formam um único movimento. O que esse processo duplo de escrever e dirigir para o trabalho de dramaturgo implica? De que maneira "dramaturgizar" com Joël Pommerat é diferente de outras práticas de dramaturgia?

\footnotetext{
1 Este verbo é um neologismo. O termo "dramaturgista" às vezes usado em Quebec ainda não é difundido na França.
} 


\section{A "dramaturgia prospectiva"}

Na maioria das vezes, a dramaturgia designa um trabalho de interpretação do texto antes dos ensaios (arquivo dramatúrgico preliminar, trabalho à mesa), hermenêutica que é prolongada em alguns casos por um acompanhamento da encenação (dramaturgia de palco ${ }^{2}$, olhar exterior). A dramaturgia consiste então em inventar um elo entre um texto e sua representação, em motivar e iluminar as escolhas para a cena. ${ }^{3}$ Funções recorrentes podem ser identificadas, cumulativas ou não, que fazem do dramaturgista sobretudo um maiêutico: um leitor que explica o contexto, a estrutura e os possíveis efeitos do texto, um documentalista que reúne em torno do texto ou do assunto um conjunto de fontes que propõe aos membros da equipe, às vezes adaptador ou tradutor, primeiro espectador que observa o ensaio e o comenta com o objetivo de evidenciar suas orientações.

Mesmo antes da "invenção" da encenação no século XIX, essa função foi iniciada por Gotthold Ephraim Lessing, no final do século XVIII, no Teatro Nacional de Hamburgo, através de sua crítica Dramaturgia de Hamburgo: "revista crítica" dedicada ao teatro e encarregada de "acompanhar cada passo que fará a arte do poeta como a do comediante". Na realidade, parece-me que esse processo de acompanhamento é transversal e compartilhado: todos os membros de uma equipe de criação realizam de uma maneira ou de outra, e mais ou menos conscientemente, dramaturgia, desde quando eles se interrogam sobre suas escolhas estéticas,

\footnotetext{
2 Nota do trad.: no original, "dramaturgie de plateau".

3 Ver especificamente Joseph Danan, Qu'est-ce que la dramaturgie?, Arles, Actes Sud-Papiers, collection "Apprendre", 2010 ; Anne-Françoise Benhamou, Dramaturgies de plateau, Les Solitaires intempestifs, 2012; Marion Boudier, Alice Carré, Sylvain Diaz et Barbara Métais-Chastanier, De quoi la dramaturgie est-elle le nom?, L'Harmattan, collection "Univers théâtral”, mars 2014.
}

sobre o sentido de colocar em jogo e suas possíveis representações. A dramaturgia é, como escreveu Bernard Dort, "um estado de espírito", uma tomada de consciência e uma prática de escolha responsável: "uma prática transversal. Não uma atividade em si." (DORT, 1986) De maneira radical, poderíamos argumentar que existem tantas definições e práticas de dramaturgia quanto equipes e processos criativos: o modo operacional está em se reinventar a cada projeto.

O fato de ele ser autor e diretor de seus textos, e ser seu próprio dramaturgista (Dramaturg), não impede que Joël Pommerat sinta a necessidade de ser acompanhado em sua abordagem. Mesmo que não seja mais "em dois tempos", a criação não exclui completamente a natureza dupla do teatro (texto e cena). Ela continua a se desenvolver de acordo com momentos e etapas com acentos específicos, mais ou menos textuais ou cênicos, coletivos ou solitários. Para Ça ira (1) Fin de Louis, acompanhei alguns desses momentos, desde a pesquisa de uma temática para o espetáculo, o desenvolvimento da escritura durante os ensaios com os atores e colaboradores artísticos, até a edição da peça. Com Pommerat desenvolvendo sua escritura durante os ensaios, principalmente através de improvisações dirigidas, meu acompanhamento também diz respeito aos atores. Para dirigir seus atores em improvisações férteis, Joël Pommerat insiste de fato na necessidade de serem "alimentados" e de que seus imaginários ganhem "músculo", graças a uma documentação abundante. Minha colaboração na dramaturgia de Ça ira (1) Fin de Louis está em grande parte relacionada a esta exigência documental, que é uma característica da abordagem criadora de Joël Pommerat: a documentação é um material indispensável para que ele possa entrar na escritura em colaboração com seus atores. O trabalho dramatúr- 
gico consiste então em propor uma matéria em potencial e em reagir às suas evoluções cênicas, mais do que iluminar uma matéria preexistente em vias de sua passagem a cena. Minha prática da dramaturgia difere assim daquela do "teatro em dois tempos". Proponho chamá-la de "dramaturgia prospectiva" e identificar quatro operações principais de seu desenvolvimento: identificar um assunto ou tema de criação, reunir material relevante para o teatro em relação a esse assunto, pensar em uma metodologia de trabalho a partir deste material, acompanhar suas diversas evoluções cênicas.

\section{Como contar uma história da qual já sabemos o fim?}

Prospectar significa primeiramente procurar, limpar, preparar o terreno. Para Ça ira (1) Fin de Louis, a reflexão começou no outono de 2013: antes da escolha de escrever sobre a Revolução Francesa, eu trabalhei principalmente em mostrar hipóteses sobre o espetáculo sustentado na economia e nos grandes chefes de Estado. Joël Pommerat planejava escrever uma epopeia, questionar os vínculos entre ideologia e ações, bem como o mito da liberdade individual. De leituras e leituras se afirmou seu desejo de trabalhar sobre a Revolução Francesa. Durante essa primeira etapa de prospecção, foi um grande prazer participar do surgimento de um projeto, ver um tema se impor e idéias se cristalizarem até suscitar um forte desejo de escritura, uma convicção (embora muitas coisas ainda sejam intuitivas) a partir da qual vai se engajar um trabalho de vários meses com uma equipe inteira.

Uma vez validada uma direção de investigação, a pesquisa dramatúrgica prospectiva se torna cada vez mais precisa para acompanhar o desenvolvimento da escritura dia a dia. Trata-se de reunir textos, icono- grafia, filmes, um conjunto de materiais que desencadearão e acompanharão o nascimento de situações e personagens até a escrita de diálogos. Para mergulhar no coração da Revolução Francesa sem preconceitos ou a opiniões pré-concebidas, Joël Pommerat queria trabalhar o máximo possível a partir de palavras diretas: discursos, atas de reuniões, correspondências, escritos. Eu então reuni fontes primárias, idéias, discursos, e não biografias comentadas ou interpretações do acontecimento. Partir dos documentos ia ser essencial para "alimentar" os atores, mas também se destacar de uma historiografia muito politizada e até partidária da Revolução, seja na tradição da esquerda, com o 1789 do Théâtre du Soleil de Ariane Mnouchkine mostrando como a revolução foi confiscada do povo, ou na leitura de François Furet, que assimila a revolução à origem do totalitarismo. Partir de arquivos e fatos (crônica) foi uma tentativa de escrever sem preconceitos nem interpretação pré-estabelecida para iniciar a criação "com inocência", como se não conhecêssemos o fim da história ou seus heróis.

Um dos primeiros grandes fundamentos do trabalho foi, portanto, o de partir o máximo possível do conhecimento dos fatos, lendo várias crônicas da Revolução dia após dia, de partir da leitura de testemunhos diretos, em particular de atas de assembléias ou de correspondências, de trabalhar sobre idéias dos revolucionários e não com base em suas biografias. Em vez de contar a história de grandes homens e eventos, Joël Pommerat queria propor uma história à altura do homem, feita em parte por anônimos ("na época, Robespierre é o Sr. Dupont", ele escreve em uma nota). Exceto Yvain Juillard, escolhido para encarnar o rei, todos os atores exploraram diferentes posicionamentos sociais e ideológicos antes de aprofundar a construção de seu(s) personagem(ns). 
Esses personagens não são decalques de personagens históricos reais, mas o resultado de uma escrita inspirada em vários arquivos e pelos próprios atores. A deputada Lefranc, por exemplo, não é Robespierre nem Marat, mas uma invenção a partir das proposições de Robespierre, Marat, Desmoulins, Lanjuinais e outros ainda, incorporados por Saadia Bentaïeb e carregados de suas próprias emoções e memórias íntimas.

Outro postulado de partida era agir como se não soubéssemos o fim: era obrigar-nos a procurar o "presente do passado", a encontrar o surgimento, o borbulhar, a incerteza, a imprevisibilidade peculiar do real revolucionário. Se a realidade é o que é percebido e interpretado, o real é precisamente o que nos escapa, "o que não cessa de não ser escrito" (Lacan), o que nos surpreende, o que nos entende mais do que entendemos. Tratava-se então de pensar novamente essa história como um problema, um enigma, para redescobri-la, em vez de desdobrar a narrativa estabelecida dos grandes momentos de uma história patrimonializada/matrimonializada.

Antes do início dos ensaios com a equipe de criação, duas oficinas de exploração abertas a atores externos à Companhia permitiram precisar essas primeiras pistas, confrontando-se aos arquivos e a diversas maneiras de teatralizá-las. A reflexão dramatúrgica serviu, assim, para elaborar hipóteses metodológicas mais do que para orientar uma "leitura" da Revolução Francesa. Mesmo que o trabalho de coleta de documentos e essa reflexão metodológica inicie antes do início dos ensaios, não se trata de uma dramaturgia prévia ${ }^{4}$ no senti-

4 Ver "Préalable " e "Dramaturgie de concept " em Marion Boudier, Alice Carré, Sylvain Diaz et Barbara Métais-Chastanier, De quoi la dramaturgie est-elle le nom ?, L'Harmattan, coll. Univers théâtral, 2014. Alguns capítulos foram traduzidos e fazem parte da publicação organizada por CALDAS, Paulo; GADELHA, Ernesto. Dança e dramaturgia(s). São Paulo, Nexus, 2016. do de uma hipótese narrativa e interpretativa que a encenação em seguida experimentaria ou concretizaria. Trata-se de uma investigação. A abordagem foi processual, tateante. $O$ estado de espírito é o da pesquisa, um questionamento permanente baseado em hipóteses, ensaios e experimentos.

\section{Fazer os arquivos falarem}

O historiador Guillaume Mazeau ${ }^{5}$ foi um colaborador essencial na busca de arquivos necessária para a escritura de palco. Primeiro o solicitei como "especialista", pensando que ele poderia dar algumas lições ou conferências aos atores, mas, finalmente, ele acompanhou toda a criação e trabalhamos em parceria, o que é uma singularidade do processo de criação de Ça ira (1) Fin de Louis. Assistidos por vários estagiários, formamos a "equipe de dramaturgia" que organizava o trabalho.

A partir das anotações de Joël Pommerat, cuja forma e conteúdo evoluem permanentemente, de início nós trabalhamos de maneira quantitativa, acumulando fontes (vários relatos de um mesmo acontecimento, vários discursos defendendo a mesma posição ou um fragmento inteiro dos arquivos parlamentares, por exemplo). Tentativa de esgotar um material inesgotável... À medida que a escrita progredia, quando grandes sequências históricas foram identificadas para se tornarem cenas, a pesquisa documental se intensificou para se tornar mais qualitativa. Para cada momento histórico dos anos 17861791 e às vezes também para ideologias políticas, compilamos arquivos documentais, reunindo grandes extratos dos Arquivos Par-

5 Guillaume Mazeau é Mestre de Conferências no Instituto de História da Revolução Francesa, da Université Paris 1 - Panthéon Sorbonne. Ele é o autor de Bain de l'histoire (Champ Vallon, 2009) e Pour quoi faire la Révolution (Agone, 2012, em colaboração com Jean-Luc Chappey, Bernard Gainot, Frédéric Regent e Pierre Serna). 
lamentares, correspondências de deputados, extratos da imprensa, diários, manifesto, petição e outras declarações orais ou escritas. Selecionamos principalmente documentos históricos nos quais pontos de vista singulares foram expressos, sejam eles do gênero do discurso, do testemunho ou do relato.

Um pensamento da transição para a cena orientou permanentemente essa seleção documental: não se trata apenas de selecionar um material historicamente pertinente, mas um material mais suscetível do que outro de se tornar teatro, um acontecimento que poderia criar uma boa situação dramática, um texto que ajudará o ator a encontrar um estado, trechos de uma correspondência a ser reescrita para extrair um ponto de vista singular... Além dos discursos, colecionei, por exemplo, uma série de detalhes e anedotas muito concretas sobre os problemas de organização da fala na Assembleia, sobre o calor, os odores, sobre as atitudes de alguns deputados... Essa dramaturgia está próxima do trabalho de um documentalista, mas difere dela por sua grande proximidade com o trabalho cênico. Ela ocorre em interação com o palco: é por isso que também uso o termo "documentação de palco" para descrever meu trabalho. O material dramatúrgico proposto influencia a direção que uma cena pode tomar e, reciprocamente, o progresso da escrita reorienta constantemente a pesquisa documental.

\section{Uma dramaturgia a serviço de} atrizes e atores ${ }^{6}$

A coleta de arquivos é uma primeira etapa antes do que poderia ser chamado de "tratamento dramatúrgico" do material para

6 Nota do trad.: no original, "comédien.ne.s", de acordo com a escrita inclusiva. designar as operações de apropriação e de transformação que levam do documento ao discurso teatral. Se algumas improvisações dos atores puderam ser guiadas diretamente a partir de fontes "brutas", outros arquivos sofreram uma primeira transformação: destaque, seleção, recorte, edição, reescrita, reformulação, colocação em perspectiva... Guillaume Mazeau e eu reescrevemos algumas fontes narrativas sob a forma de breves discursos para facilitar o acesso às atrizes e aos atores. Nós compilamos listas de elementos de linguagem extraídos desses arquivos. Também conseguimos "fabricar fontes", mesclando textos ou recontextualizando certos argumentos (e, neste caso, a presença do historiador era essencial para não trair a história): vários discursos do deputado conservador Malouet, do Terceiro Estado, sintetizados em uma página, por exemplo, ou os argumentos tidos em 1793 contra a violência utilizados para trabalhar uma cena com o mesmo tema, mas situada em 1789.

Os arquivos documentais também contêm documentos pertencentes a outros períodos históricos. Por exemplo, em um dossiê dedicado à violência revolucionária: os textos de Marat sobre tumultos populares, Robespierre sobre o direito à insurreição, a petição de Pauline Léon pelo armamento de mulheres e textos mais contemporâneos, como uma seleção de Crônicas da Revolução Egípcia, de El Aswany, por seu chamado ao engajamento e à descrição de crimes policiais, textos da Fração do Exército Vermelho sobre a guerrilha urbana... Também trocamos links no Youtube mostrando manifestações no Egito e Tunísia, a confraternização da polícia com manifestantes, imagens do INA ${ }^{7}$ sobre os tanques soviéticos em Praga em 1968... Esses anacronismos controlados funcionam como analogias

7 Nota do trad.: Institut National de l'Audiovisuel. 
com o objetivo de ajudar os atores a entrarem nas emoções e nos estados extremos.

A transmissão de documentos às atrizes e aos atores, através da organização de arquivos documentais, leituras coletivas à mesa ou entrevistas individuais, é um momento essencial para que o arquivo se torne um meio de imaginação e um real combustível para a escrita. Sem o arquivo, os atores esbarravam em aproximações ou clichês. Inversamente, sem seus imaginários e seus corpos que permitiam representar o passado, devolvendo a efetividade do tempo presente vivido, o arquivo permaneceria mudo. $\mathrm{Na}$ abordagem de Joël Pommerat, a improvisação direcionada permite esse processo de apropriação, interpretação e compreensão dos arquivos. Dois grandes eixos metodológicos surgiram gradualmente para a improvisação: um trabalho individual de produção de discurso político, a encenação coletiva de situações históricas. Com os discursos individuais, buscávamos identificar os critérios de uma ("verdadeira") palavra política, o menos fabricado possível, para evitar que as atrizes e os atores reproduzissem posturas políticas. Era uma questão de dar-Ihes textos para "carregá-los" e "ganharem músculo8 politicamente" antes das improvisações coletivas dirigidas. Essas improvisações solitárias de discursos eram para as atrizes e os atores se apropriarem do conteúdo de um arquivo e reformulá-lo. Tratava-se de memorizar o conteúdo, os argumentos, e não um texto como um todo, a fim de serem capazes de improvisar a partir dele. Ao fazer isso, as atrizes e atores podiam tomar a liberdade em relação ao registro do hipotexto, traduzir, modernizar a linguagem da época. Ao acumular vários discursos de uma mesma tonalidade e cor políticas, se fazia pouco a pouco emergir um personagem: por exem- plo, ficamos particularmente impressionados com um discurso de Barthes sobre "a superioridade da raça nobre" reimprovisada pelo jovem Simon Verjans. Em seguida, nós Ihe demos vários discursos reacionários para ele trabalhar: Burke, Seinac de Meilhan e até contemporâneos como Mauras ou Finkel kraut. Assim foi construído o personagem do deputado da nobreza De Lacanaux, contra-revolucionário muito ativo durante as últimas negociações para evitar que o Terceiro Estado formem a Assembleia Nacional ou quando da chegada de mulheres de Paris a Versalhes. O caminho da escrita parte então dos discursos para ir em direção ao personagem através do ator e tudo o que ele traz reimprovisando a fonte. Esse trabalho de improvisação do discurso solitário nem sempre resultou em um tipo ou identidade, mas possibilitou especificar possíveis posições ideológicas e emocionais, identificar temas e argumentos, imaginar debates ou situações.

Para as improvisações coletivas dirigidas, Joël Pommerat indicava, por exemplo, um momento ou uma data, um local, temas a serem abordados (a noite de 13 de julho, em uma reunião de bairro em Paris, a violência, o medo, a fome...) e distribuía os atores ou pedia a eles que escolhessem um posicionamento (o homem politizado moderado, uma mulher preocupada com sua sobrevivência, um homem politizado radical partidário da violência armada, um indeciso...). Dessa forma, sem saber, às vezes fizemos história contrafactual: ao final de uma improvisação localizada em 14 de julho, a Bastilha não foi tomada! A improvisação como exploração das possibilidades de uma situação histórica nos permitiu compreender melhor as interações entre as diferentes forças presentes $\mathrm{e}$ sentir a surpresa ou a urgência da tomada de decisão nesse contexto. Por meio da improvisação, os documentos do passado deixa-

8 Nota do trad.: no original, "muscler". 
ram de ser apenas do passado para se tornarem novamente o "futuro não realizado".

Retomada e aprofundada por vários dias, a improvisação permitia lançar uma primeiro roteiro ou sinopse das cenas, bem como fragmentos de diálogos a partir dos quais Joël Pommerat escrevia. Joël Pommerat prefere escrever a partir do que observa e sente em cena: ele coloca em forma certos elementos que ocorreram no palco ou propõe outra coisa; não se trata da estenografia do discurso improvisado. A escrita se desenrola através de uma dinâmica de palimpsestos sucessivos a partir de documentos históricos através de várias etapas coletivas de pré-escrita ("tratamento dramatúrgico" do material, improvisações dos atores) e depois de reescritura solitária por Joël Pommerat. Na dinâmica de criação colaborativa da Companhia Louis Brouillard, o dramaturgista não tem autoridade quanto ao saber e ao texto; nisso cada um e cada uma contribui a seu modo, através do jogo, dos figurinos, da documentação, etc., a partir das indicações dadas por Joël Pommerat, que define e assina o espetáculo no final do processo.

Joël Pommerat queria escrever uma "ficção verdadeira" baseada em acontecimentos históricos, como dramaturgista, eu me propus a tarefa de ser uma espécie de vigia para esse oxímoro: fornecer verdade, o real, fatos históricos, arquivos, sem nunca perder de vista o fato de estarmos fazendo teatro, uma verdade fabricada, não científica, mas humana e sensível. Concebo a dramaturgia prospectiva e documental antes de tudo como uma ferramenta prática, inspiradora e enriquecedora que, sendo precisa e exaustiva o mais possível, deve encontrar eficiência cênica, produzir jogo, estados emocionais, experiências de pensamento. "Que todo mundo seja seu próprio

9 Ver Paul Ricœur, Temps et récit 3. Le temps raconté, Paris, Seuil, coll. Point, p. 329-348, 1991 (1985). historiador. Então se viverá com mais cuidado e condições", como dizia Brecht... ${ }^{10}$

No duplo contexto pós-moderno do fim das grandes narrativas emancipatórias (J.-F. Lyotard) e do teatro pós-dramático (Lehmann), Ça ira (1) Fin de Louis reafirma o gosto de Joël Pommerat pela narrativa. Ao romper com os códigos da epopéia, ele propõe aos espectadores uma experiência: à "altura dos homens", desconstruindo o mito e a herança, ele nos convida a reviver o passado como presente e nos lembra o quanto a democracia continua sendo um desafio para a atualidade.

Referências

BENHAMOU, Anne-Françoise, Dramaturgies de plateau, Les Solitaires Intempestifs, 2012.

BOUDIER, Marion, Avec Joël Pommerat, un monde complexe, Actes Sud-Papiers, coll. "Apprendre", 2015.

BOUDIER, Marion; CARRÉ, Alice; DIAZ, Sylvain; MÉTAIS-CHASTANIER, Barbara, De quoi la dramaturgie est-elle le nom ?, L'Harmattan, collection "Univers théâtral", mars 2014.

DANAN, Joseph, Qu'est-ce que la dramaturgie?, Actes Sud-Papiers, collection "Apprendre", 2010.

DORT, Bernard, L'État d'esprit dramaturgique, Théâtre/ Public, nº 67, 1986.

GOUHIER, Henri, Le Théâtre et les Arts à deux temps, Flammarion, 1989.

10 Jean-Luc Godard citando Bertolt Brecht ao final de Tudo vai bem, de 1972. 
LESSING, Dramaturgie de Hambourg [1769], trad. J.-M. Valentin, Klincksieck, coll. "Germanistique", 2010.

RICCEUR, Paul, Temps et récit 3. Le temps raconté, Seuil, coll. Point, 1991 (1985).

TACKELS, Bruno, Les Écritures de plateau. État des lieux, Les Solitaires Intempestifs, 2016.

Recebido: 02/09/2019

Aprovado: 02/11/2019 